\begin{tabular}{cc}
\hline $\begin{array}{l}\text { CURRENT } \\
\text { WORLD }\end{array}$ & ISSN: 0973-4929, Vol. 12, No. (2) 2017, Pg. 429-435 \\
CNVVrRonment & $\begin{array}{c}\text { Current World Environment } \\
\text { Journal Website: www.cwejournal.org }\end{array}$ \\
\hline & Weather Modeling Using Data-driven Adaptive \\
Rough-Neuro-Fuzzy Approach
\end{tabular}

\title{
M. SUDHA
}

Associate Professor, Dept. of Information Technology, VIT University, India.

\begin{abstract}
Recently, hybrid data-driven models have become appropriate predictive patterns in various hydrological forecast scenarios. Especially, meteorology has witnessed that there is a need for a much better approach to handle weather-related parameters intelligently. To handle this challenging issue, this research intends to apply the fuzzy and ANN theories for developing hybridized adaptive rough-neuro-fuzzy intelligent system. Assimilating the features of ANN and FIS has attracted the rising attention of researchers due to the growing requisite of adaptive intelligent systems to solve the real world requirements. The proposed model is capable of handling soft rule boundaries and linguistic variables to improve the prediction accuracy. The adaptive roughneuro-fuzzy approach attained an enhanced prediction accuracy of $95.49 \%$ and outperformed the existing techniques.
\end{abstract}

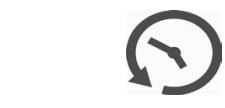

Article History

Received: 26 April 2017 Accepted: 16 July 2017

\section{Keywords:}

Rainfall prediction, Data-driven approach, fuzzy and neural network.

\section{Introduction}

In rough set, data analysis starts from a table referred to as decision or information table representing an information system ${ }^{30}$. A wide range of scientific and medical applications, especially in the field of pattern recognition, data mining, machine learning and process control systems adopted the rough set as a suitable tool ${ }^{29}$. Zadeh introduced Fuzzy set theory to the researchers and mathematicians in 1967 stating that, it is not required to have a precise, numerical information input for modeling a system ${ }^{40}$. This research applies Fuzzy inference system that maps a given input to output using the fuzzy sets theory that uses Sugeno method ${ }^{24}$. The artificial ANN
(ANN) model was developed by Rosenblatt in $1958^{31}$. The functionalities of ANN resemble the human brain and acquire knowledge through a learning process. As a recent trend adaptive neuro fuzzy inference system (ANFIS) is widely used for modeling daily rainfall prediction ${ }^{18}$. A Modified ANFIS used modeling rainfall events at the Klang River basin; in Malaysia reported better accuracy².

ANNs and fuzzy logic approach applied for forecasting weather in different areas of china reported that the prediction accuracy achieved by the proposed models was satisfactory than other existing methods ${ }^{4,5}$ Applied ANFIS for forecasting drought, the model reported improved for forecast accuracy ${ }^{6}$.

CONTACT M. Sudha msudha@ vit.ac.in 9 Associate Professor, Dept. of Information Technology, VIT University, India. (C) 2017 The Author(s). Published by Enviro Research Publishers

This is an 6 Open Access article licensed under a Creative Commons Attribution-NonCommercial-ShareAlike 4.0 International License (https://creativecommons.org/licenses/by-nc-sa/4.0/), which permits unrestricted NonCommercial use, distribution, and reproduction in any medium, provided the original work is properly cited.

To link to this article: http://dx.doi.org/10.12944/CWE.12.2.27 
Most of the Data-driven model may increase the rainfall prediction accuracy ${ }^{20,16}$ Applied ANFIS model to predict rainfall. ${ }^{15}$ Developed a neuro-fuzzy model to predict the monthly rainfall at Daejeon in Korea. Application of neuro-fuzzy model to forecast annual drought conditions in the Maharlu-Bakhtegan watershed, reported neuro-fuzzy model as a suitable method ${ }^{7,9}$ Applied ANFIS in the forecasting of the ground water level of Bastam Plain in Iran. ${ }^{10}$ developed ANFIS for modeling long-term streamflow forecasting in Dez basin, Iran. ANFIS applied to predict rainfall in Khorasan Razavi reported ANFIS as suitable tool ${ }^{11}$.

The apparent advantage of ANFIS is, it can capture the benefits of both models in a single framework ${ }^{13}$. ANFIS model used for forecasting the monsoon rainfall in the region Junagadh (India) revealed neuro-fuzzy as a superior model ${ }^{18,17}$, it is reinstated that the performance of fuzzy inference system and artificial ANN based are better than existing approaches used for flood forecasting. Applied a rough set based fuzzy ANN algorithm for weather prediction and reported better accuracy the other existing model ${ }^{19,21}$ Stated that ANFIS perform groundwater level prediction more accurately when compared to ANNs. ${ }^{22}$ Reviewed the applicability of ANFIS models for rainfall forecasting in southeast Australia.

Likewise, an assessment conducted on rainfall event evaluation using neuro-fuzzy inference system for Mashhad reported ANFIS as a suitable model for forecasting ${ }^{25}$. The performance evaluation of Neuro-fuzzy and ANN models showed fuzzy model as a most suitable mode ${ }^{26}$. A neuro-fuzzy weather prediction model combining fuzzy logic for rainfall-runoff modeling at Kranji basin in Singapore outperformed the existing approach ${ }^{37,36}$ Reviewed the applicability of fuzzy in industrial processes modeling and monitoring. Neuro model are also adopted for river flow ${ }^{8}$. The literature reports revealed that Fuzzy and ANN systems are widely applied in weather forecasting currently ${ }^{28}$. The last decade has perceived the benefits of application of ANFIS in various hydrological predictions ${ }^{23}$

\section{Materials and Methods}

In this investigation, the ANFIS model is examined using the above stated input methods to achieve enhanced prediction rate. In this study, initial weather inputs before feature reduction consists of eight observational parameters: $\left\{\mathrm{O}_{\mathrm{p} 1}\right.$ : maximumtemperature), $\mathrm{O}_{\mathrm{p} 2}:$ minimum temperature, $\mathrm{O}_{\mathrm{p} 3}$ : relative humidity $1, \mathrm{O}_{\mathrm{p} 4}$ : relative humidity2, $\mathrm{O}_{\mathrm{p} 5}:$ windspeed, $\mathrm{O}_{\mathrm{p} 6}$ : solar-radiation, $\mathrm{O}_{\mathrm{p} 7}$ : sunshine and $\mathrm{O}_{\mathrm{p} 8}$ : evapotranspiration\}.

The complete feature set is used to find the reducts to enhance the learning potential of proposed roughneuro-fuzzy inference (ARNFA) system. Later, an exhaustive subset search generates all possible combination of subsets reducts $\left\{\mathrm{O}_{\mathrm{p} 2}, \mathrm{O}_{\mathrm{p} 4}, \mathrm{O}_{\mathrm{p} 5}, \mathrm{O}_{\mathrm{p} 6}\right.$, $\left.\mathrm{O}_{p 7}\right\},\left\{\mathrm{Op} 2, \mathrm{O}_{\mathrm{p} 3}, \mathrm{O}_{\mathrm{p} 4}, \mathrm{O}_{\mathrm{p} 7}, \mathrm{O}_{\mathrm{p} 8}\right\}$ and $\left\{\mathrm{Op} 2, \mathrm{O}_{\mathrm{p} 3}, \mathrm{O}_{\mathrm{p} 4}\right.$, $\left.\mathrm{O}_{\mathrm{p} 6}, \mathrm{O}_{\mathrm{p} 7}, \mathrm{O}_{\mathrm{p} 8}\right\}$ to determine the possible effective observational parameters in modeling rainfall prediction. ANFIS maps the input members to an intended input membership function and then input MF to a set of if-then rules. The derived output rule set characteristics are mapped to output memberships, and the output MFs are converted to single valued decision associated with the output ${ }^{12}$.

\section{ARNFA Enhanced Data-driven Prediction Model}

The proposed ARNFA is a sequentially hybridized model integrating rough set based feature selection and neuro-fuzzy inference based predictive method. In FIS, fuzzy rules are applied to deduce a new approximate fuzzy set conclusion while taking a fuzzy membership as the foundation. FL approaches are mainly applied to the imprecise scenarios that are tough to be designed precisely as in this proposed rainfall prediction scenario. The application or if the studying issues are vague then fuzzy inference system can be the most suitable model ${ }^{39,14}$ Stated that ANFIS is a feed forward neural network and is constructed by supervised learning. Assimilating the features of ANN and FIS has attracted the rising attention of researchers due to the growing requisite of adaptive intelligent systems to solve the real world requirements ${ }^{1}$.

ANFIS maps the input members to an intended input membership function and then input MF to a set of ifthen rules. The derived output rule set characteristics are mapped to output memberships, and the output MFs are converted to single valued decision associated with the output ${ }^{12}$. The computational time complexity and number of rules will increase related to the number of input variables. The biggest problem in ANFIS is if the inputs are high in the number exceeding five, the system will fail to model output exactly on inputs. 


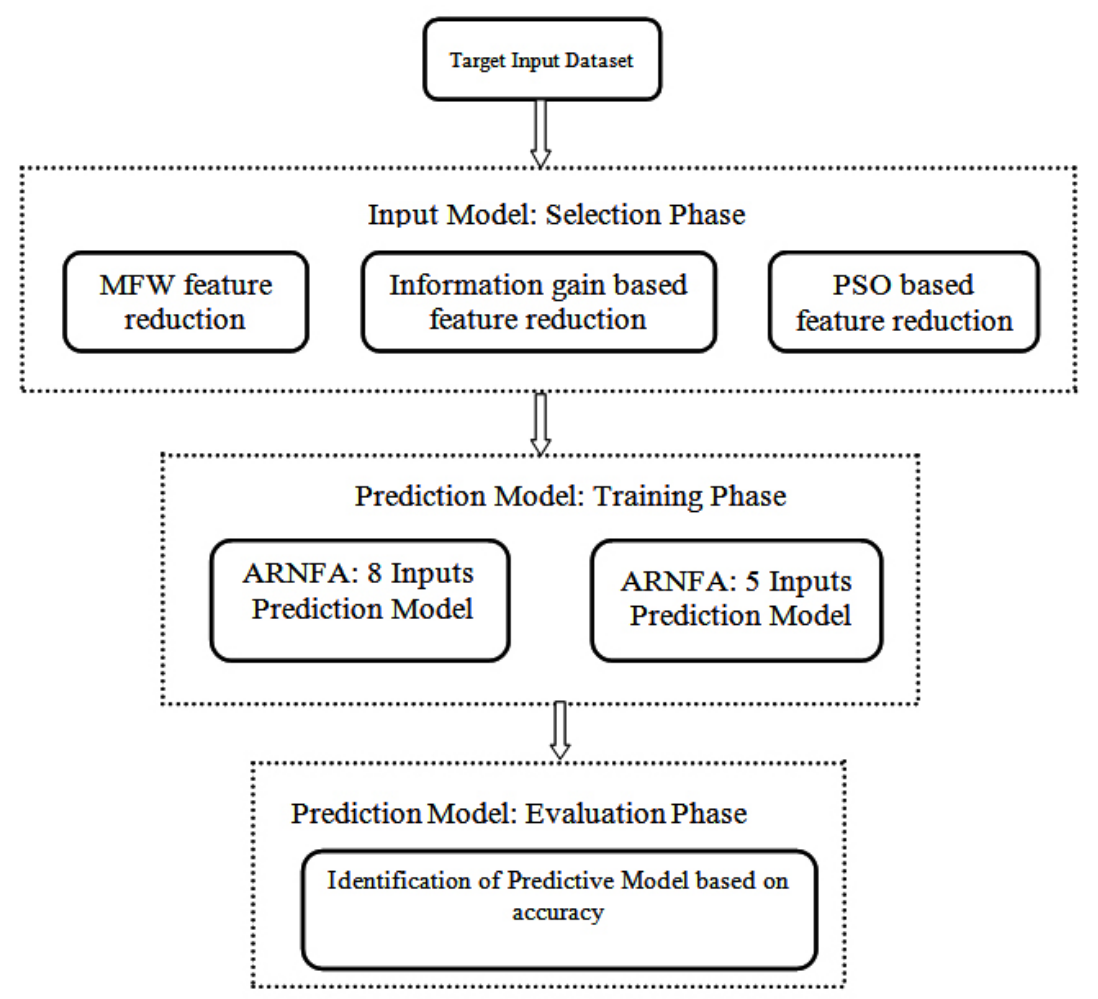

Fig. 1: Adaptive rough neuro fuzzy approach based Hybrid intelligent system

\section{Input Data Selection Phase - ARNFA}

Rough computing based maximum frequency weighted reduct selection approach is used for identifying the most relevant weather parameter to improve the learning potential of neuro-fuzzy system. This proposed input selection approach is benchmarked with the proven Information-gain and particle swarm optimization search. Feature selection is an intensive task; these techniques have improved the performance of training algorithms while minimizing the errors due to superfluous input values $^{33,34,35}$. The feature subsets generated using maximum frequency weighted reduct selection (MFWFR); information gain (IG) and particle swarm optimization (PSO) approaches are used for input selection $^{32}$. In the model training phase, the feature reducts generated using input selection models are used for training the algorithms. This datadriven hybrid system as in Figure. 1 is evaluated by complete and reduced feature input to demonstrate the importance of feature reduction. The proposed model regulates the premise parameters sets to facilitate adaptive neuro-fuzzy inference systems output to match the training data. In the model training phase, the feature subset (reduct) generated using three input data models are used for training the learning algorithms. Adaptive neuro-fuzzy inference system, fuzzy rule-based classification techniques and recent evolutionary classification models are for used training the models for rainfall prediction. To identify the best blend of input parameters to attain the desired precision, the optimal reducts of the complete feature set computed using rough set based maximum frequency weighted reduct selection, information gain and PSO based feature selection are evaluated.

FIS used in ARNFA has five processing levels such as: fuzzification, production, normalization, defuzzification, and aggregation layer with following input and output relationships for each layer ${ }^{27}$. The ARNF model performance evaluated against existing techniques in the model evaluation phase. The bench marked classification methods apart from adaptive network based fuzzy inference system are evaluated using WEKA (Waikato Environment for Knowledge Analysis) ${ }^{38}$ and KEEL (Knowledge Exploration using Evolutionary Learning) ${ }^{3}$. The comparative study of the ARNFA and existing models are shown in 
Table1.

To identify the best blend of input parameters to attain the desired precision, the optimal reducts of the complete feature set computed using rough set based maximum frequency weighted reduct selection, information gain and PSO based feature selection are evaluated. The last decade has perceived the benefits of application of ANFIS in various hydrological predictions ${ }^{23}$.

\section{ARNFA-Learning and Evaluation Phase}

In the model training phase, the feature subset (reduct) generated using three input data models are used for training the learning algorithms. Adaptive neuro-fuzzy inference system, fuzzy rule-based classification techniques and recent evolutionary classification models are for used training the models for rainfall prediction. The proposed model performance is estimated and evaluated against existing techniques in the model evaluation phase. Apart from adaptive network based fuzzy inference system, the other learning techniques are evaluated using WEKA ${ }^{38}$ and KEEL ${ }^{3}$. The bench marked PSO, ACO and fuzzy rule-based classification methods are evaluated using KEEL and WEKA. The comparative study of the proposed model against these existing models is shown in Table 71.

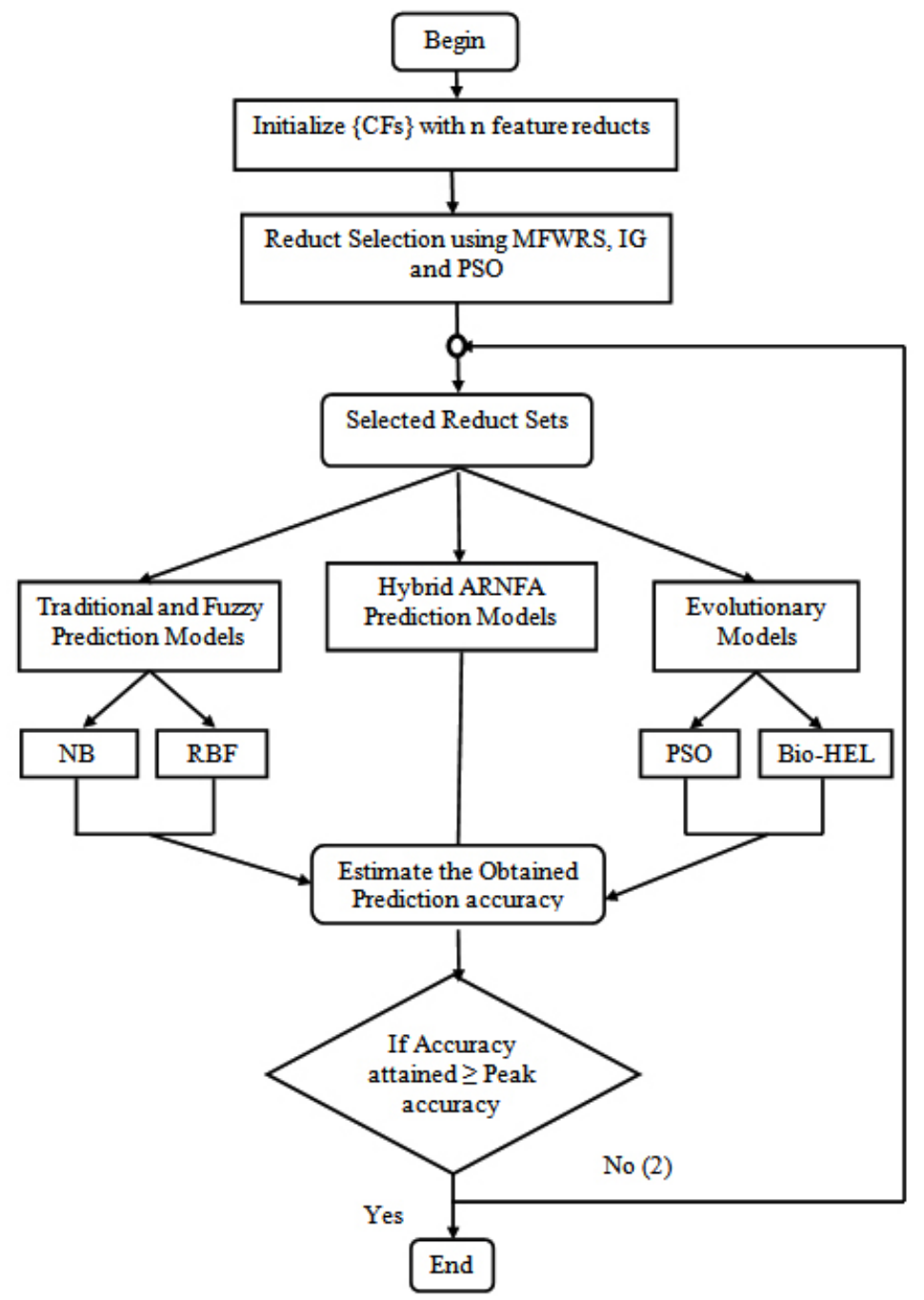

Fig. 2: Adaptive rough neuro fuzzy approach process flow design 


\section{Results and Discussions}

The accuracy rate acquired by the classification models before and after for the reduction is projected in Table1. Experimental results indicate that accuracy rate of the classification models has improved after feature reduction. When compared to existing generic evolutionary and fuzzy rule-based classification approach. Performance evaluation outcomes have identified ARNFA as a suitable model for rainfall prediction.

Table 1: Prediction accuracy existing vs proposed hybrid model.

\begin{tabular}{|c|c|c|c|c|}
\hline Classifier & $\begin{array}{l}\text { Before Feature } \\
\text { Selection }\end{array}$ & $\begin{array}{c}\text { After Feature } \\
\text { Selection (MWFR) }\end{array}$ & $\begin{array}{l}\text { After Feature } \\
\text { Selection (IG) }\end{array}$ & $\begin{array}{c}\text { After Feature } \\
\text { Selection (PSO) }\end{array}$ \\
\hline \multicolumn{5}{|c|}{ Tradition Supervised Learning Approach } \\
\hline NB & $81.89 \%$ & $79.97 \%$ & $82.05 \%$ & $82.22 \%$ \\
\hline RBF & $80.98 \%$ & 80.61 & $82.21 \%$ & $82.65 \%$ \\
\hline SVM & $80.05 \%$ & $80.39 \%$ & $78.59 \%$ & $79.25 \%$ \\
\hline \multicolumn{5}{|c|}{ Fuzzy based Supervised Learning Approach } \\
\hline FR3 & $83.44 \%$ & $82.23 \%$ & $83.83 \%$ & $83.81 \%$ \\
\hline FLR & $61.23 \%$ & $61.14 \%$ & $61.07 \%$ & $61.05 \%$ \\
\hline FuzzyNN & $82.97 \%$ & $82.64 \%$ & $80.74 \%$ & $83.55 \%$ \\
\hline \multicolumn{5}{|c|}{ Evolutionary Supervised Learning Approach } \\
\hline PSO-ACO & $83.45 \%$ & $82.72 \%$ & $83.80 \%$ & $83.45 \%$ \\
\hline CPSO & $74.10 \%$ & $79.50 \%$ & $79.79 \%$ & $74.10 \%$ \\
\hline BIOHEL & $82.50 \%$ & $82.50 \%$ & $82.50 \%$ & $85.10 \%$ \\
\hline \multicolumn{5}{|c|}{ Proposed Hybrid Adaptive Rough Neuro Fuzzy Approach } \\
\hline ARNFA & $88.90 \%$ & $95.49 \%$ & $89.75 \%$ & $92.05 \%$ \\
\hline
\end{tabular}

The proposed ARNFA achieved $95.49 \%$ accuracy when trained using the feature reduct generated using MFWRS algorithm. The proposed model outperformed when trained using rough set based maximum frequency weighted feature reduct than information based feature reduction and PSO approach.

\section{Conclusion}

Most of the generic classification techniques report substantial improvement in prediction accuracy. But the attained precision is considered to be insignificant for modeling real-time hydrological forecast. This investigation concludes that global prediction approach as an insignificant tool in modeling regional hydrological forecasts. Therefore, a domain-specific hybrid architectures integrating rough, fuzzy, evolutionary and neuro computing at various stages are proposed to achieve the desired prediction precision.

\section{Acknowledgement}

I would like to show my gratitude to the school of Information Technology and Engineering, VIT University for resources and supports during the course of this research, and I thank the "anonymous" reviewers for their so-called insights. I am immensely grateful to their comments on an earlier version of the manuscript.

\section{References}

1. Abraham, A. (2001). Neuro fuzzy systems: State of the art modeling techniques,
Connectionist Models of Neurons, Learning

Processes, and Artificial Intelligence, Lecture 
Notes in Computer Science, Springer Berlin Heidelberg, pp. 269-276.

2. Akrami, S. A., A. El-Shafie Abraham and O. Jaafar (2013). Improving rainfall forecasting efficiency using modified adaptive neurofuzzy inference system (MANFIS), Water Resource Management, vol.27 pp.35073523.

3. Alcala-Fdez, J., R. Alcala and F. Herrera (2011). A fuzzy association rule-based classification model for high-dimensional problems with genetic rule selection and lateral tuning, IEEE Transactions on Fuzzy Systems, vol.19(5) pp.857-872.

4. Al-Matarneh, L., A.Sheta, S. Bani-Ahmad, J. Alshaer and I. Al-oqily (2014). Development of temperature based weather forecasting models using neural networks and fuzzy logic, International Journal of Multimedia and Ubiquitous Engineering, vol.9(12) pp.343366

5. Bacanli, U. G., M. Firat and F. Dikbas (2009). Adaptive neuro-fuzzy inference system for drought forecasting, Stochastic Environmental Research and Risk Assessment, vol.23 pp.1143-1154.

6. Cheng, C.T., C. P. Ou and K. W. Chau (2002). Combining a fuzzy optimal model with a genetic algorithm to solve multi-objective rainfall-runoff model calibration, Journal of hydrology, vol.268(1) pp.72-86.

7. Choubin, B., S. Khalighi-Sigaroodi, A. Malekian, S. Ahmad and P. Attarod (2014). Drought forecasting in a semi-arid watershed using climate signals: a neuro-fuzzy modeling approach, Journal of Material Science, vol.11(6) pp.1593-1605

8. Choudhury, X. and P. Roy (2015). Forecasting concurrent flows in a river system using ANNs, Journal of Hydrologic Engineering, vol.20(8) pp.1-7.

9. Emamgholizadeh, S., K. Moslemi and G. Karami (2014). Prediction the groundwater level of Bastam plain (Iran) by Artificial Neural Network (ANN) and Adaptive Neuro-Fuzzy Inference System (ANFIS), Water Resource Management, vol.28 pp.5433-5446.

10. Esmaeelzadeh, S. R., A. Adib and S. Alahdin (2015). Long-term stream flow forecasts by adaptive neuro-fuzzy inference system using satellite images and k-fold cross-validation (Case Study: Dez, Iran), KSCE Journal of Civil Engineering, vol.19(7) pp.2298-2306.

11. Fallah-Ghalhary, G. A., M. Habibi-Nokhandan, M. Mousavi-Baygi, J. Khoshhal and A. S. Barzoki (2010). Spring rainfall prediction based on remote linkage controlling using adaptive neuro-fuzzy inference system, Theoretical Applied Climatology, vol.101 pp.217-233.

12. Hayati, M., A. M. Rashidi and A. Rezaei (2011). Prediction of grain size of nano crystalline nickel coatings using adaptive neuro-fuzzy inference system, Solid State Science, vol.13(1) pp.163-167.

13. Hipni, A., A. El-shafie, A. Najah, O. A. Karim, A. Hussain and M. Mukhlisin (2013). Daily forecasting of dam water levels: comparing a Support Vector Machine (SVM) model with Adaptive Neuro Fuzzy Inference System (ANFIS), Water Resource Management, vol.27 pp.3803-3823.

14. Huang, C.L., N. S. Hsu, C. C. Wei and C. W. Lo (2015). Using artificial intelligence to retrieve the optimal parameters and structures of adaptive network-based fuzzy inference system for typhoon precipitation forecast modeling,Advances in Meteorology, 2015, pp.1-22.

15. Jeong, C., J. Shin, T. Kim and J. Heo (2012) Monthly precipitation forecasting with a neurofuzzy model, Water Resource Management, vol. 26 pp.4467-4483.

16. Kisi, O., J. Shiri and M. Tombul (2013). Modeling rainfall-runoff process using soft computing techniques, Computers and Geosciences, vol.51 pp.108-117.

17. Kumar, R., N. K. Goel, C. Chatterjee and P. C. Nayak (2015). Regional flood frequency analysis using soft computing techniques, Water Resource Management, vol.29 pp.1965-1978

18. Kyada, P. M. and P. Kumar (2015). Daily rainfall forecasting using adaptive neuro fuzzy inference system models, International Journal of Science and Nature, vol.6(3) pp.382-388.

19. Li, K. and Y. Liu (2005). A rough set based fuzzy neural network algorithm for weather prediction, Proceedings of International 
Conference on Machine Learning and Cybernetics, Guangzhou. pp.1888-1892

20. Lu, J., S. Xue, X. Zhang, S. Zhang and W. Lu (2014). Neural fuzzy inference system-based weather prediction model and its precipitation predicting experiment, Atmosphere, vol. 5 pp.788-805.

21. Maiti, S. and R. K. Tiwari (2014). A comparative study of artificial neural networks, bayesian neural networks and adaptive neuro-fuzzy inference system in groundwater level prediction, Environmental Earth Science, vol.71 pp.3147-3160.

22. Mekanik, F., M. A. Imteaz and A. Talei (2015). Seasonal rainfall forecasting by adaptive network based fuzzy inference system (ANFIS) using large scale climate signals, Climate Dynamics, vol.45(1) pp.1-15.

23. Nayak, P. C., K. P. Sudheer, D. M. Rangan, and K. S. Ramasastri (2005). Short term flood forecasting with a neuro fuzzy model, Water Resources Research, vol.41(1) pp.1-16.

24. Negnevitsky, M. (2005). Artificial Intelligence: A Guide to Intelligent Systems. Pearson Education Limited, Essex, England.

25. Niksaz, P. and A. M. Latif (2014). Rainfall events evaluation using adaptive neural fuzzy inference system, International Journal of Information Technology and Computer Science, vol. 9 pp.46-51.

26. Oyediran, O. F. and A. B. Adeyemo (2013). Performance evaluation of neural network MLP and ANFIS models for weather forecasting studies, African Journal of Computing \& ICT, vol.6(1) pp.147-164.

27. Panchal, R., T. M. V. Suryanarayana and F. P. Parekh (2014). Adaptive neuro-fuzzy inference system for rainfall-runoff modeling, International Journal of Engineering Research and Applications, vol.4 pp.202-206.

28. Pant, L. M. and A. Ganju (2004). Fuzzy rulebased system for prediction of direct action avalanches, Current Science, vol.87(1) pp.99104.

29. Pawlak, Z. (2002). Rough Sets and its Applications, Journal of Telecommunications and Information Technology, vol. 3 pp.7-10.

30. Pawlak, Z. (1982). Rough sets, International Journal of Computer and Information
Sciences, vol.11(5) pp.341-356.

31. Rosenblatt, F. (1958). The perceptron: a probabilistic model for information storage and organization in the brain, Psychological review, vol.65(6) pp.386.

32. Sudha, M. (2017). Intelligent decision support system based on rough set and fuzzy logic approach for efficacious precipitation forecast, Decision Science Letters, vol.6(1) pp.96-105.

33. Sudha, M. and B. Valarmathi (2016). Identification of effective features and classifiers for short term rainfall prediction using rough set based maximum frequency weighted feature reduction technique, Journal of Computing and Information Technology. vol. 24(2) pp.181-194.

34. Sudha, M. and B. Valarmathi (2015). Impactof hybrid intelligent computing in identifying constructive weather parameters for modeling effective rainfall prediction, AGRIS on-line Papers in Economics and Informatics, vol. 7(4) pp.151-160.

35. Sudha, M. and B. Valarmathi (2014). Identification of significant attribute set from multivariate rainfall data using principle component analysis, International Journal of Applied Environmental Sciences, vol. 9(4) pp.1595-1602.

36. Takagi, T. and M. Sugeno (1985). Fuzzy identification of systems and its applications to modeling and control, IEEE Transaction on Systems Man and Cybernetics, vol. 1 pp.116132.

37. Talei, A., L. H. C. Chua and C. Quek (2010). A novel application of a neuro-fuzzy computational technique in event-based rainfall runoff modeling, Expert Systems with Applications, vol.37 pp.7456-7468.

38. Witten, I. H. and E. Frank (2005). Data Mining: Practical Machine Learning Tools and Techniques, Morgan Kaufmann, San Francisco, 525.

39. Yang, Z., Y. Liu and C. Li (2011). Interpolation of missing wind data based on ANFIS. Renewable Energy, vol.36(3) pp.993-998.

40. Zadeh, L.A (1965). Fuzzy Set, Information and Control, vol.8 pp.338-353. 